\title{
Geography, Ontological Politics and the Resilient Future
}

\author{
Abstract \\ Applications of 'resilience' have stretched it to the point of breaking, yet it still maintains a \\ remarkable capacity to organise relations in diverse fields of geographical concern such as \\ ecological management, development, security, psychology, and urban preparedness. Critical \\ takes on resilience have emphasised its neoliberal roots and utility. While we do not disagree \\ with this stance, our critical intervention argues that there are multiple resiliences invoking \\ differing spatialities, temporalities and political implications and that this multiplicity is an \\ important part of the work that 'resilience' can do. We explore diverse mobilizations of \\ resilience thinking across a wide array of empirical domains drawing out the differing \\ ontological bases of resiliences and the interventions meant to promote them, particularly \\ given the tension between a desire for open, non-linearity on the one hand and a mission to \\ control and manage on the other. Rather than take resilience to be a determinedly new shift in \\ policy-making, we explore how the post-political qualities of 'resilience multiple' can enable \\ changes in behaviours and practices that slide between conflicting and contestable visions of \\ the good life and desirable futures. We argue that the only way to critically interrogate \\ resilience is to force the question of particulars in its diverse articulations, and, thus, \\ geographers should engage in debating the ontological politics of resilience multiple.
}

Keywords: Resilience, socio-ecological systems, psychology, security, multiple, post-political 


\section{Introduction}

The resilience concept has demonstrated its own extraordinary resilience. Applications have stretched it to the point of breaking, and yet it still maintains a remarkable capacity to discursively frame and organise relations in diverse fields of geographical concern such as ecological management, development, security, psychology, and urban preparedness. The remarkable prevalence of the resilience concept is tightly bound to the adage that we now live in a 'time of crisis.' It has come to stand for the ability to absorb, withstand, persist, and even thrive and reorganise in the face of the shocks and disturbances of always uncertain becoming, that is now even 'more so.' Resilience is being offered as the solution to incredibly challenging societal problems and a key organising concept in the zeitgeist of uncertainty. This has significant geographical implications as 'resilience' widely influences spatial formations and shapes contemporary understandings of social-ecological relations. Wendy Larner (2011) has argued that even as we must be critical of totalizing neoliberal and crisis narratives that claim uniqueness and novelty-as resilience invocations also often do-we must attend to the ways in which contemporary crisis narratives rearrange political forms and spatial relations (2011: see also Neocleous, 2012; Swyngedouw, 2010). In this spirit, borrowing from Annemarie Mol's understanding of ontological politics and 'the body multiple' (2002), this paper interrogates the geographical and political implications of multiple resiliences, which nonetheless 'hang together', and it locates at least two axes along which 'resilience' can be ontologically interrogated and made to name names, as elaborated below. 
This task of interrogating the ontological politics of resilience is particularly important because uses of the term could generally be characterized by a post-political gloss of benevolence and desirability, which erases deeply antagonistic questions of security, care, and responsibility. Resilience is perhaps part of "a new lexicon of words with ambiguous meanings" that obscure "any inconsistency between narrating the turbulent future as governable or ungovernable, or opportunity or threat" (Amin, 2013: 141), to which we would add the ambiguities that arise when such concepts slide between ecological, economic, and security logics (Cooper 2006, 2010; de Goede and Randalls, 2009; Massumi, 2008). Reghezza-Zitt et al.'s (2012) review of the use of resilience in hazards research ends up marking out what resilience is not rather than constructing a positive definition. Thus, when one digs down into its everexpanding uses, 'resilience' frequently rings hollow even though some versions have more specific referents, such as in social-ecological systems science. There is no inbuilt, attendant, or assumed set of actors, referents, values, or politics to the term. While resilience may sound good therefore, especially in comparison to disparaged terms such as security and intervention, the flexibility of the term does significant work to gloss over the diverse ways in which it is deployed and what its uses might enable.

Thus, rather than reigning in the concept, our analysis of resilience multiple is inspired by the explosion of resilience deployments, which have different geographies and temporalities, diverse effects and different kinds of political implications. Our starting point is that there is no singular resilience argument as this does not bear out in the multiple ways resilience is used to navigate contemporary crisis politics. But, further, we argue that the 
important point is not simply to highlight multiplicity or to de-universalise, but to expose resilience as a post-political term of art that has to be taken to task at its points of articulation. We maintain that the way in which resilience deployments are and can be politicized is by forcing specifications of ontology, site, intervention, and responsibility at its points of articulation. While we sympathise with critiques arguing that resilience is fundamentally neoliberal, these arguments universalize in a way that can obscure the remarkable breadth of resilience proselytizers and, crucially, the elasticity of resilience politics, which could be potentially even more nefarious than if it were only a neoliberal instrument. If the term is ultimately without referents in many of its current uses, dare we say meaningless, identifying the ontological, epistemological and power assumptions of its uses may well be the only universal moment for politicizing the concept.

Drawing on wide-ranging examples and literatures from social-ecological systems (SES), security, health, psychology, religion and other domains the paper explores the ontological politics of resilience multiple. To paraphrase Mol (2002), we understand resilience multiple as 'more than one' but not ultimately fragmented into 'many'. By looking at the ways resiliences diverge and hang together, we draw out the concept's ontological politics, which need to be interrogated wherever it is invoked. To demonstrate this more empirically we deploy two analytical 'cuts' across the examples. First, we ask, where do proponents 'site' resilience, where is it located, and where can it be 'found'? This question is of fundamental importance to understanding how all resiliences frames responsibility, security, and care. Resilience ontologies have normative implications. Second, we ask, how is resilience encouraged to 
proliferate? If it is supposed to be a 'self-flowering' characteristic that allows things, systems or persons to flourish when left to their own devices, then what are the active moments of intervention that mean to craft it? We maintain that this tension between intervention and self-flowering is a crucial point for understanding the power dynamics of all resiliences. Our analytical cuts are deliberately wide-ranging, slicing across a number of different disciplines and fields of practice, in order to reveal ontological politics at stake in geographical literatures and beyond. Finally in conclusion we point towards ways of politicizing resilience multiple.

\section{Approach: The ontological politics of resilience multiple}

There are no easy answers to where and how resilience appears. Variously a psychological trait, community asset, urban quality, ecological property, development strategy, and so on, these resiliences 'that go by a single name' (Mol, 2002: 84) can be many different things, imagine many different futures, and inspire different interventions and, yet, are all drawn under the same banner. It is in this sense that we argue resilience is multiple (as with Anderson, 2015). It is not a pre-given object but a generality with ontological flexibility. Its definitive generality makes it amenable to do almost anything, thus, its invocation doesn't necessarily do any one thing or another.

In her ethnography of the disease atherosclerosis in a Dutch hospital, Mol details how the disease is enacted multiply and yet rendered provisionally singular and actionable through certain procedures. Her careful rendering covers a complex human and more-than-human field of practice where multiple atheroscleroses come into view. However, rather than being 
fragmented, the disease still 'hangs together' through 'forms of coordination' (2002: 55). Multiple does not mean plural. As Mol writes, the body multiple is 'more than one, but not fragmented into being many' (2002: viii). Similarly, even as we argue that resilience is multiple, the vague attribution of a singular good-the 'assumption of singularity' -is important for how it does work, for its 'world-making effects' (Blaser 2012: 54). While we do not argue that people conceptualize resilience as singular, it is nonetheless an accomplishment that the term hangs together across such a wide variety of domains, and "as long as incompatible [resiliences] do not meet, they are in no position to confront each other" (Mol, 2002: 119). Different disciplines and broad areas can retain a faith in resilience that belies crucial differences.

Our approach differs from Mol's long-term ethnography, where she 'privileges practices over principles' and focuses on everyday enactments. It would certainly be possible to study the practice of resilience multiple in particular, situated contexts. But we submit that there is also something about how the concept of resilience has been taken up in such diverse, scattered, contradictory sites and domains that is important for understanding its conditions of possibility. Thus we draw from many domains, which we cannot delicately render in all of their complexities, nor situate in their particular contexts or day-to-day work. This is a product of our extensive literature search, both in formal academic and Internet-based work. In the following sections we draw from resilience deployments in psychology, security, socialecological systems and other fields, which can make for strange bedfellows and some crude generalizations. However, we maintain that there is a commonality across this distribution, which is the generality and flexibility of 'resilience' that names a positive future, or desirable 
conditions of possibility, yet makes no promises. Our examples focus on idealized and programmatic articulations, but these ideal articulations should not be seen as divorced from 'real' resilience. Rather, we maintain that these idealizations, visualizations, and articulations make resilience what it is: they bring it into being, grant it capacities, which are not given but emerge-or don't emerge, or emerge differently-in practice.

At this juncture, one might question whether these articulations are merely diverse discourses (an epistemological question) and whether resilience has simply become a polysemous concept that creates a 'semantic blur' (Reghezz-Zitt et al., 2012). Might we establish 'real' resilience from other deployments? There is significant examination of this within socio-ecological systems (SES) research, a field that has done much to develop and espouse resilience thinking. It can be seen in calls for rigour and clarity in the use of the term (Carpenter et al., 2001) and to ponder the potential of constructing a theory of resilience that would enable the creation of a set of principles that could be applied to guide resource management (Anderies et al., 2006; Walker et al, 2006). There are also questions about the challenges of matching an SES approach with other forms of resilience thinking, for example with questions of agency in psychological literatures (Berkes and Ross, 2013; Coulthard, 2012; Davidson 2013). To provide an exemplar of this. For Berkes and Ross (2013) the psychological literatures, with a focus on individual resilience, provide a more in-depth social science to complement approaches to community resilience in SES research. While supportive in principle of reconciliation, Davidson (2013), on the other hand, considers their proposal to suffer from an inadequate conceptualization of agency as individual resilience is sacrificed for the 
development of community resilience. This tension is not merely a reflection of different discourses. The frictions encountered in trying to integrate just these two different disciplinary resilience concepts underscores our argument that differing ontological conceptions between academic domains (let alone beyond academia) creates sufficient tension in itself to warrant careful examination of the ontological politics of resilience multiple.

We maintain that conceptualizing resilience multiple is particularly important because there is an equal tendency to reify resilience as an object in contemporary critique.

Predominantly, it has been read as a neoliberal object, born out of and perpetuating neoliberal logics, conditions, and relations (Walker and Cooper, 2011; Evans and Reid, 2014; Joseph, 2013). For example, Jeremy Walker and Melinda Cooper (2011) trace resilience through the work of ecologist C.S. Holling and the uptake of complexity thinking in ecosystem science and place it in relation to contemporaneous Hayekian neoliberals' attention to irruptive and nonlinear dynamics of capital. Walker and Cooper suggest an instrumental deployment of complexity thinking in neoliberal thought and detail the ways in which non-equilibrium concepts are taken up in limit-denying, self-referential arguments aiming to seize upon inevitable crises of capitalism. Resilience is cast as a neoliberal term of art that buttresses a disavowal of any promise of societal security, devolution of responsibility to the individual, an ideal of self-organisation without intervention, normalisation of crisis, and financialisation of moments of crisis as sites of capital accumulation (Cooper 2010; Mirowski, 2013).

We accept the claim that there is "an intuitive ideological fit" between neoliberal philosophies and resilience logics (Walker and Cooper, 2011: 144) since many of the calls for 
resilience in fields such as development and urban studies, while often couched in the language of community self-determination, are profoundly conservative and systemically selfreferential. As Mackinnon and Derickson (2012: 254) put it: "resilient spaces are precisely what capitalism needs-spaces that are periodically reinvented to meet the changing demands of capital accumulation in an increasingly globalised economy." But, we want to suggest that this critique only goes so far. The argument that resilience is neoliberal crafts a foothold for critique but it can also obscure what 'resilience' can do, how it is done, and, sometimes, how it is neoliberal in particular situations. It gives resilience a coherence that is questionable and while it could be said that its generality and dispersal is precisely evidence of its neoliberalness, this does not tell us so much about how resilience comes to be enabling and how to interrogate it. To be clear, our aim is not to refute these critiques as we have taken inspiration from them. Nor is our aim to rescue or recraft resilience. It is also not our contention that resilience could or should be recrafted for progressive ends (Nelson, 2014).

Rather, our aim is to articulate the ontological politics of resilience multiple, "a politics that has to do with the way in which problems are framed, bodies are shaped, and lives are pushed and pulled into one shape or another" (Mol, 2002: viii). It has to do with the 'conditions of possibility,' or the 'positivity,' which give things their form and 'mode of being' (Foucault, 2002: 378). Put differently, John Law calls ontological politics: "a politics about what there is in the world... what there might be in the world. An interference for the kinds of things that might exist in the world. Between the singular and the plural" (2002: 198). Resilience is not ontologically given, even though deployments often grant it a singularity that erases 
controversy, friction, choices, options, and decisions. Through resilience generality, "fragments of a large number of possible orders glitter separately" (Foucault, 2002: xix), are made potential, through one and the same word. Thus, our aim is to draw out the productivity of that singular generality: its multiple world-making potentialities. The political in ontological politics explicitly engages with the question of interference, with what kind of crisis politics and relations to the present and future are brought into being through enactments of 'resilience'.

Politically, 'resilience' can do a diversity of things under the cloak of generality. For example, it is often invoked in discussions of poverty. Writing about poverty amongst families, Karen Seccombe (2002) argues for understanding resilience in social and structural terms, where resilience to poverty should be facilitated through wealth redistribution and strong social welfare policies rather than through the study of individuals who are perceived as adaptive in the face of poverty. In sharp contrast, the World Bank roots resilience to poverty in 'the rural poor' who bear the burden of developing resilience through enterprising activity (World Resources Report 2008; see Reid, 2012). While there are clearly differences in terms of the influence and reach of these different understandings, they illustrate the divergent political visions that 'resilience' can mobilise. Alternatively consider the classic example of resilience in ecological thought. While it has been deployed in socio-ecological systems literatures as a critique of destructive resource management or exclusionary policies rooted in equilibrium theories, geographers have emphasized that there is no progressive politics necessarily embedded in non-equilibrium ecologies or 'adaptive management' (Adams, 1997; Cote and Nightingale, 2012; Nadasdy, 2007; Zimmerer, 2000). 
As a 'bridging concept' (Coaffee, 2006), resilience is said to have an arranging and coordinating function. It is offered as an organizing principle and a solution that can purportedly beneficially connect whatever needs to be bridged across space and time (see also Wilson, 2012). Spatio-temporal imaginaries of resilience are expansive. As Gunderson and Holling write (2002: 21): "The processes we need to understand, and in some way integrate, literally cover months to millennia, meters to tens of thousands of kilometres." From underwater to outer space, 'resilience' is given the task of spanning and drawing connections across these expansive geographical and temporal imaginaries, rearranging things in the present in the name of inevitable crises of the future. This future is articulated in the gleaming promise of what the American Psychological Association calls the 'road to resilience' suggesting it could be arrived at in the future even while denying the possibility of completely 'having' or 'reaching' it. The 'road to resilience' is politically ambiguous, we suggest, because resilience rendered as a singular generality is ultimately agnostic as to what it joins up, where it might span, who makes it so, how it might get there, why this is good.

The significance of this generality is that what makes resilience, what it actually is, can be fashioned from appeals or references to anything that is functioning or alive. In terms of ontological politics, we might ask what 'conditions of possibility' this generality portends and what it means in terms of 'interfering' among these possibilities (Mol, 1999: 74). In order to draw out the ontological politics of resilience's generality, we find inspiration in understandings of contemporary 'post-politics' developed variously by theorists of contemporary political subjectivity. Post-politics refers to a political condition defined by a lack 
of antagonism and, in its place, decision-making by consensus and technocratic management, which assumes the inevitability of existing capitalist relations. Politics takes the form of minor tweaks here and there from experts aimed at the administration of narrowly defined social matters. The space for major 'acts' or moments of reversal and openness are sutured (Žižek, 2001: 11). Here, 'the political' is foreclosed, which is ultimately defined by unavoidable antagonism, confrontation, and demands (as distinguished from policies or mere politics) (see Dikeç, 2005). Žižek elaborates on this distinction: "One can also put it in terms of the wellknown definition of politics as the 'art of the possible': authentic politics [the political] is, rather, the exact opposite, that is, the art of the impossible - it changes the very parameters of what is considered 'possible' in the existing constellation" (1999: 199).

Our point here is not to establish whether or not resilience is post-political, but to establish the productive elements these discussions provide for thinking through what resilience multiple does or can do. Drawing from Swyngedouw's (2010) understanding of postpolitics, we find two interrelated points of inspiration for interrogating the conditions of possibility of resilience multiple: 'resilience' arouses positive visions of the future and yet it makes no egalitarian or democratic demands. On the first point, 'resilience' suggests a positive condition even as it reifies an insecure or crisis-ridden world; it engages positive affects of societal security beyond fear and neurosis (Adey and Anderson 2012). Unlike the 'apocalypse forever' of climate change post-politics (Swyngedouw 2010), 'resilience' suggests a positive relation to a crisis-ridden future. We are not arguing that 'resilience' actually produces the secure relation it arouses, but that, politically, it resides in the empty space of this purely 
negative relation to the future that Swyngedouw describes. This is the irrefutability of resilience: casually, at first glance, what is there to argue about the desirability of 'being resilient'? This is related to the second point, it names a positive relation to the future (defined by crisis as it may be) but it makes no demands. Resilience gives no 'proper names' and it makes no promises. Without the demand, "nothing really has to change" (ibid: 223). This is the power of agnostic resilience-that it simultaneously names the 'cure' and names nothing substantial at all. Further, and in line with neoliberal resilience critiques, when it makes an appeal to the future that is rooted in the present, to minor tweaks and the 'administration of social matters' (Žižek, 1999: 199), its 'conditions of possibility' are located in maintaining the present condition not in fundamentally changing existing frameworks.

However, we would caution against ending the story here. 'Resilience' does not necessarily reproduce the status quo nor does it necessarily signal an ultimate foreclosure of politicization. The potential to politicize resilience-towards dramatically different projects (Nelson, 2014)-should caution against writing off the political work that its use can do or is doing to remake the present and future. The key moments lie in recognizing the conditions of possibility that different resilience invocations open up or foreclose; in interrogating ontological politics at points of articulation and identifying the difference that 'resilience' makes in particular moments.

Our purpose in the following sections is to demonstrate how and where resilience deployments name names; can be made to name names. This project applies as much to critical readings as to those wishing to resuscitate or recapture resilience as a way of imagining 
and crafting more just and equitable futures. In our analysis below, we locate two axes along which ontological politics of resilience can be interrogated: ontological sitings or locations and the interventions meant to shape or craft it.

\section{Cut 1: Ontological sitings: Where is resilience and how did it get there?}

Resilience has been described as a capability, quality, outcome, tool, ideological instrument, thing, process, posture, and an inherent property. In this section we argue that what 'resilience' is is fundamentally tied to where it is said to be or come from, and, further, that these spatial ontologies are inherently linked to the conditions of possibility of resiliences. As Mol emphasizes, the 'question about where the options are is so relevant to ontological politics" (1999: 80). The political work of siting resilience, of locating or 'finding' it in one place and not another, and determining 'where the options are' is fundamental to its world-making effects.

Health scholars Aranda et al. (2012) make useful distinctions between three common ontological sitings of resilience, drawing inspiration from Rortyian philosophy and health literatures. First, they identify 'resilience found' as a framing that locates resilience in inherent, inert capacities of individuals or systems. In these articulations, its de facto good can be 'discovered,' as it is located, a priori, in the resilient subject. The growth of genetic resilience in disease treatment experimentation is one example. 'Found' resilience frameworks can work positively to reward those who 'possess' it, while also requiring strategies to cope with those 
less well endowed. Thus companies might intervene upon highly sensitive workers who are less resilient in the turbulent $21^{\text {st }}$ century business environment, or indigenous groups might be encouraged to seek psychological connections that "allow communities to access the resilience of their ancestors" (Landau, 2007: 355).

Aranda et al. (2012) identify a second form called 'resilience made,' which is about practices rather than inherent properties; here, resilience is not discovered but nurtured. In 'made' framings, things and people can be made resilient through an engagement of environmental factors and hearts and minds. Consider, for example, the wealth of self-help websites geared toward fostering psychological resilience. MeQuilibrium offers a self-help system to create internal fortitude to deal with life's little problems. The Climate Psychology Alliance offers therapy for those struggling to become resilient to the mental anguish of a changing climate. 'Resilience made' is also evident in the proliferating efforts to teach or train for resilience, particularly in security domains. For example, the FBI literature offers tips for to teach and discipline the resilient subject through 'a training of the mind' (Larned, 2012). The US Department of Homeland Security commissioned a study of how Israel is supposedly able to instil resilience to terrorism in the psyche of the population, crediting success to training programmes targeting children in kindergarten: "starting terrorism education from an early age ensures that the necessity of preparedness is internalized in the psyche of every member of society" (Homeland Security Institute, 2009: 22). 'Made' suggests an active process of crafting and working toward resilience, ideally in relation to environmental factors, events, or stressors. 
Aranda et al. (2012) argue that there is a third, more analytical siting in play: 'resilience unfinished'. Here they describe a poststructural resilient subject, ambiguous, reflexive, and with an embodied and affective biography. The resilient subject is produced through a set of practices and behaviours and is always already unfinished such that subjects embody, learn, instill, and generate resilience, however defined. We could think about, for example, the production of new kinds of 'neurotic citizens' (Isin, 2004) or affective, resilient subjects (Grove, 2014), unsure of whether they are resilient enough in the face of crisis. Most important, this frame draws out the interminable horizon of resilience imperatives, always just out of reach, subject to changing environmental relations and constant revision, which further generalizes its indefinite field. The use of resilience language in Christian circles, literally a 'gospel of resilience' (Nadasdy, 2007), is a good example. Christian resilience thinking draws on biblical examples, in particular that worshippers 'have heard of the patience of Job' (James, 5:11) and recasting Paul as being a resilient man in the face of troubles and difficulties. This framing casts psychological resilience, a sound and faithful mind, as the pre-eminent form of endurance. This is a faith based ontological politics in which the 'promises' of 'resilience' are located in future expectations. Some believe the most faithful may be more resilient to life's problems through the hope or confidence in an afterlife (resilience unfinished at least while on earth).

While Aranda et al.'s (2012) distinctions are useful, in some deployments resilience can be found, made, and unfinished all at once. Consider for example, one of the author's tests results for the 14-Item Resilience Scale ${ }^{\mathrm{TM}}$ test, ${ }^{i}$ which is actually used in academic psychology research. With a score of 68 out of a possible 98 , part of the author's online test report stated, 
"Your resilience level is on the low end but this doesn't mean you have zero resilience. Everyone is resilient to some degree." The scale is of several minds about the siting of resilience. It asks for gender, age, and general health, which, along with the admission that 'everyone' is at least somewhat resilient, would seem to suggest 'found.' But scores are based on self-reported assessments of personality traits and how one might handle situations that could arise: asking how determined you are, if you believe in yourself, and to what degree you "usually manage one way or another." Further, a wealth of psychology research developing country specific, culturally specific versions of the test all suggest 'made'. The entire enterprise in which some psychologists identify incredibly broad self-reported traits as evidence of something called 'resilience,' which is both possessed and cultivated through practice and mindfulness, demonstrates the 'unfinished' nature of it all. What the scale avoids explicitly discussing is what it would mean for an individual to not 'have' resilience, to have to go out and 'get' it, or craft a life around pursuing it. That the term could be defined through such different ontological locations, within even just this one example, evidences the divergent conclusions to be drawn or options to be had in the name of resilience. Interrogating the spatialities of these articulations, the different worlds they invoke and make, forces questions such as what and who is included and excluded, where responsibility or capability comes from, what are the thresholds of what one must bear or absorb, and, were this possible, which subjects have the abilities and time to re-make themselves to become resilient.

We argue that resilience analysts should take these kinds of deployments to task precisely to force more specific and political questions about the imagined ontology of 
resilience and the good life that is at stake and the bads to be avoided. Thus one key moment in discerning the particular antagonisms and claims of resilience deployments is to locate where it is said to reside and how it got there. For example, are humans resilient or are some humans resilient (e.g. along geographic ('Americans') or circumstantial ('the poor') lines)? How did they come to be that way, were they born with it or did they learn to be resilient through trials, learning, or necessity? The answers to these kinds of questions offer moments of specificity for nailing down the ontological politics, demands, and promises of resiliences. Who or what is asked to become resilient, who is deemed to 'be resilient', how did they obtain this, can others get it, who claims to 'give' it or teach it, and so on?

One example, which is distinctively open about its implications, is psychologist Michael Ungar's 'social ecology' approach to resilience (2011). He specifies this approach in the case of childcare thusly:

'One can hypothesize that if we grew the environment-for example, by providing well-subsidized quality public day care for all children under the age of 5-we could create the optimal conditions for more resilient children...The day care, if culturally relevant, potentiates the development of resilience. Whether an individual child benefits specifically is not the core issue; rather, the fact that the day care is there, and the possibilities for change it provides for working and socially isolated parents, creates a social ecology where more positive development can be expected' (2). Here, resilience does not reside, found or made, in day care spaces or in individual parents and children. Resilience is potentially enabled through socio-spatial relationality; it is a desired 
possibility that could only emerge from the production of spaces of positive development. It names the positive value: communal responsibility for and expectation of societal security and care. Further, it names how this positive value could be enabled: well-subsidized public day care. This example is somewhat rare in resilience parlance because it very openly bares its ontological assumptions, names its values and desired future, and articulates tactics and interventions. These elements are what must be uncovered by resilience critiques and openly articulated by those wishing to mobilize it politically.

The unfinished (Aranda et al., 2012) project of resilience multiple structures its ontological politics. If it is not really possible to demarcate resilience from being functional, this delimits an incredibly expansive field; one that does not necessarily provide much traction for meaningful demands or promises. In short, resilience seems to be found wherever it might be said to be found and summoned whenever benign, affirming feelings are needed or desired. Resilience is thus remarkably elastic concept, variably cast as a property/capacity of things themselves and yet something to be engineered, engaged, or enhanced. Even as many who deploy these perspectives seek to foster, grow, instil, and develop it in systems, people, communities, material things, etc., we might reasonably ask, what things are alive or functioning, which are not 'resilient'? It appears in many literatures as a matter of degrees (more or less resilient), but without much sense of what these conditions would look like. Next we turn to the power relations in resilience interventions, focusing on how it is 'encouraged' to proliferate in diverse ways. 


\section{Cut 2: Interventions: How is resilience encouraged to proliferate?}

Interventions to enhance resilience reflect the multiple ontological politics of its deployments. Resilient traits are said to include self-healing, and inherent features like flexibility, grace, absorbency, dynamism, resourcefulness, and invention. If resilience is said to follow from the inherent properties and immanent relations of self-organizing systems, then how do actors, perhaps outside of these systems, intervene within them? This is of crucial importance, because while systems, individuals, and phenomena are said to be most resilient when left to their own devices, this has not meant that things are always or even usually left to develop themselves. The resilience ambition has not completely displaced ideas of control (Thomsen et al. 2013). Climate change policy still fixates on the 2 degrees temperature target; for all the calls to experimentation, much of conservation ecology is still determinedly preservationist in approach (Cabin, 2007); for all the risk-taking advocated, patients may be unimpressed by the "clinical gaze...[that] reinforces personal responsibility for fostering resilience" (Aranda et al., 2012: 560); and for all the talk of cyber resilience and the desirability of letting it alone, the explosive growth of the cybersecurity industry obsessively pursues ways to reign in and guide emergent cyber relations. Here is one of the ways in which we can expose, intervene in and shape the politics of resilience at its points of articulation.

We focus on the tension within all resiliences between ideas of 'self-healing' immanent environmental relations and the reality of intervention and interpretation. Importantly, advocates rarely just let things be, as the connotation of benevolent generality and selforganisation might suggest. What we see instead are active projects of crafting and directing 
relations. Resilience is rarely invoked without recommendations for how to build resilience. As the Department of Homeland Security puzzlingly reports, "Resilient self-healing systems require a complete overhaul" (2004: 14). Perhaps socio-ecological systems scholar Brian Walker best sums up this tension in his description of the term: "The essence of resilience.... is to understand feedbacks that keep it self-organizing in the way we want it to be" (2009, emphasis added). This fundamental tension of resilience projects, between the ideal of immanent emergence and the reality of active intervention, begs the question, who defines how 'we want it to be'? How are the 'self' and the 'inherent' actively crafted? And what then are the implications of this tension when the appeal to resilience arranges relations? We argue that this moment of tension is one of the key openings for interrogating the ontological politics of resilience. Uncovering and unpacking moments of intervention reveal the underlying assumptions and productions of what is often cast as the natural unfolding of inherent, selforganizing relations.

Here we draw on two examples in more depth to illustrate the way in which resilience is encouraged to proliferate in two particular arenas: ecology and security. First, geography and politics literatures commonly reference resilience as an ecological concept and draw from ecologist C.S. Holling's early work (1973)." Holling argued that ecosystems are complex and non-linear rather than stable and tending toward equilibrium and, further, sought to account for the ability of ecosystems to maintain cohesion even through extreme disturbances. There can be no singular state of stable equilibrium with neatly nested hierarchies and clear causal relationships that can be identified from the outside. Rigid extraction and management 
practices focused on control, Holling and his contemporaries argued, made ecosystems less resilient and more brittle. Instead, they advocated adaptive management approaches that are flexible to changing circumstances, immanent properties of ecosystems, and that effectively learn by doing.

This conceptual work leads to interventions and practices that are designed to encourage a positive proliferation of resilience. In the ecological literatures, SES scholars note that resilience interventions may be as much an art as science (Anderies et al., 2006) and that while basic science is important, models can only be evaluated in policy terms or outcomes through management actions that test the success of possible interventions. This places emphasis on experimentation and a retreat from certainty when acting to conserve or restore ecosystems. For example, Gross (2010) argues that ecological restoration must embrace the unexpected; surprises are likely when reintroducing species or recovering contaminated or industrial sites. As Gross notes in the case of the 'magic hedge' in Chicago, a non-native species of hedge that should have been removed if following the standard restoration principles of privileging native species, remained in place as a bird habitat and played a crucial role in enabling the restoration of the prairie landscape in the rest of the site. This message is re-iterated in work on the experimentation required in managing the ecology of cities (Evans, 2013) and equally major rewilding projects such as the Oostvaardersplaasen in the Netherlands, an experimental ecological reserve with re-wilded (de-domesticated) Heck cattle, to create a landscape that would reflect the paleoecology of the times of the extinct Aurochsen (Lorimer and Driessen, 2013). Perhaps the most complete statement of 
experimentation in ecology is provided by Cabin (2007) who proposed that one way of testing the success of ecological restoration projects would be to establish an area and allocate plots to different people with different ideas. Each year, an ecological assessment could be made and those plots that were successful could then be expanded into the plots that were unsuccessful. In other words, we simply see what happens. All of these examples highlight the directed nature of ecological interventions that at the same time tap into the idea that nature will run its course. Resilience is proven through trials of experimentation that show the systems are functioning to sustain life and that they are functioning in the way 'we want them to be.'

In resilience experimentation approaches, a core political question is what and who is enrolled to support and deliver the required interventions to enable those experiments. In Gross' (2010) case, the restoration ecologists had to agree to compromise with birdspotters on the survival of the magic hedge and therefore had to relinquish a sense of the ecological sanctity of native species in restoration projects. Contrastingly, ecologist Frans Vera had the position, power and access to be able to support the rewilding at Oostvaardersplassen. Resilience through experimentation has no singular politics. Multiple politics and futures emerge from these approaches. Deliberation and collaborative expertise, bringing together environmental, economic and social domains, often termed adaptive governance, can be a form of positive transformation to engineer new futures rather than return to vulnerable pasts (Young, 2010; see also Nelson, 2014). But resilience experiment interventions are not always about transformational change; indeed they can also intensify the status quo (Reghezz-Zitt et 
al., 2012). Nonequilibrium ecology can be politically progressive or conservative;

experimentation can be resisted, transformed and can fail (Castan Broto and Bulkeley, 2013);

resilience can embrace collaboration or cement unequal social relations. Interventions need to be interrogated for their specific effects in particular articulations and experiments, rather than resort to overarching generalities.

If ecological resilience interventions are turning to experimentation, one rough equivalent in security is redundancy and absorption, or the possibility for multiple pathways of recovery and coordination to emerge before, during, or after events. Here, the ideal for resilience interventions is that they might foster an "in-built adaptability to the fluid nature of the new security threats" (Coaffee, 2006). Paralleling understandings of complex, non-linear systems, contemporary security framings revolve around notions of emergence and incomplete knowledge:

'Threats are unpredictable and the full range of threats probably unknowable. We will never be able to anticipate all possible threats and even if we could, there is not enough money to deploy technologies to address them. Security in this situation needs to be flexible and agile and capable of addressing new threats as they emerge' (Little, 2004: 57).

'Resilience' as security is anticipatory in the sense that disruptions are viewed as inevitable, but it is not preemptive or preventative; this evolving vulnerability is to be 'lived with'. For example, infrastructure security agendas in the US, UK, and EU explicitly wish for self-healing systems and security that is emergent, inherent, and 'designed in.' The security sector borrow 
quite liberally from ecological and biological concepts to argue for letting systems find their own pathways. For example, one US report states that: 'To achieve the strategic goal of selfhealing, self-sustaining $\mathrm{Cl}$ [critical infrastructure] networks, automated responses to electromagnetic disturbance, laser, and particle beam weapons will need to suppress, divert, redirect, re-profile and otherwise "morph" the attacked system into a form that can survive the event' (Department of Homeland Security, 2004: 34). The report longingly references traits such as 'graceful stealth' (19) and outlines goals such as new manufacturing processes and materials science 'that may be patterned after biological processes' (14). It details the desirable traits of nanotechnology innovations that mimic the outer protection of shellfish, soil as a model of self-healing, and the productive possibilities of processes like DNA and RNA replication.

When these qualities and processes are translated into social and technological domains, interventions become fuzzy and indistinct. Common descriptors of resilience interventions include: sensing, smart, embedded, autonomous, autonomic, intuitive, and inherent. Here, intervention is written out, as security seems to merely tap into 'natural' or 'found' qualities and operate independently of guiding hands. This is not the case, however, as intervention is vital. Resilience as security always involves active shaping and intervention'suppressing, diverting, redirecting, morphing' - that comes to define 'inherent' properties. For example, the Department of Homeland Security's "Resilient Electric Grid" initiative is testing superconductor cables that might replace existing copper wire infrastructures. The hope is that the cables would allow substations to automatically distribute excess capacity during 
emergencies, thus avoiding surges and major power failures. In this case, development of inbuilt flexibility is a project that emboldens spending on private sector research and development. The Resilient Electric Grid is partnered with the private company Consolidated Edison, but one program manager states: 'There are a lot of components to this system so there are a lot of places for others to get in' (Michael, 2012). These places 'to get in' on the resilience security project expose the active interventions and shaping of 'self-organizing' and 'self-healing' systems. Interventions that supposedly enable self-organisation must be inserted 'in the middle of events' (Barry, 2006) and integrated with human interventions, knowledge frames, and power relations that fundamentally shape how resilience resources are distributed and focused. One task for resilience analytics is to expose the ways that appeals to the 'natural' obscure political choices in particular articulations.

Resilience interventions have to articulate when something is 'resilient enough,' which also bares assumptions about exposure, agency, and responsibility for risk-taking. Pushing our analysis more broadly again and to illustrate the kinds of ontological politics wrapped up in discussions of interventions, consider Brian Walker's elaboration on the essence of ecological resilience. He gives the example of exposing children to dirt and dust in their environments in order to increase their resilience to disturbances from the environment: 'The way you maintain the resilience of a system is by allowing it to probe its boundaries...[by] disturbing and probing the boundaries of resilience' (Walker, 2009). Active intervention is to test the boundaries. In parts of psychology, similarly, resilience is a capacity that emerges precisely as one is exposed to adversity. For example, Garmezy et al (1984) posit a 'challenge model' of 
children's' stress resistance wherein exposure to "stress is treated as a potential enhancer of competence" as long as it is not excessive. An American Psychological Association report on resilience and African American adolescents highlights the importance of emphasizing protective factors rather than risk, whereby young people can be considered "at promise" as opposed to "at risk". In this recasting, certain factors 'traditionally considered risk factors-can be reconceptualized as adaptive or protective processes' (2008: 3). E. James Anthony's early and influential writings on this exposure/resilience relation are particularly illuminating:

'Those coming from a stable, constant, and consistent background may overreact to change as a stressor, although, at the same time, the environmental constancy may have induced sufficient resilience for them to withstand this. Individuals emerging from rapidly changing environments may be expected to respond to powerful environmental shifts resiliently, but their uncertain environments may have brought about high degrees of vulnerability, so that they may be among the first to succumb to disastrous circumstances' (1987: 36 , emphasis added).

Here, persistent risk exposures experienced by vulnerable persons are recast as potentially positive moments for enhancing adaptability. Likewise the resilient economic subject is expected to take risks to innovate (O'Malley, 2010). But as Grove (2014) argues, the resilient subject is not necessarily simply a neoliberal subject, as appeals to resilience offer many opportunities to digress and transgress previous norms. In metal and metalcore music, for example, sorrow and stress is valorised as resilience (As I Lay Dying's song Resilience has a six word chorus that reads 'Suffering, Persistence, Such Sorrow, Yet Resilience' while the metal 
group Drowning Pool have an album entitled Resilience). Calls for resilience can therefore take rather different political forms in terms of the interventions required to achieve it.

Some trials of resilience, however, take on a rather different social and political character. Phelan et al. (2013) draw out their concept of 'perverse resilience' where a fossil fuel economy becomes internally resilient despite seeming to fall out-of-line with ecological health, an argument that highlights the vexed political agendas around intervention: resilience in the fossil fuel economy proliferates through existing power relations that make an ecological model of resilience look potentially radical and threatening to capitalist interests. Phelan et al. suggest that resilience can become negative, a system that is too resilient to change for the 'better good'. 'Resilient systems' can have collateral damage and be destructive for some interests or living things. Interventions to prop up capitalism, in this example, can sediment internal contradictions and emergent aberrance, as much as encouraging 'naturally' positive traits to flourish. This is why interventions to enhance resilience are a form of ontological politics: they implicitly or explicitly articulate a desirable future world.

There are common frictions across the interventions of various resiliences appearing in music scenes, socio-environmental systems, security, business and psychology interventions. There is a tension throughout between advocating for self-determination and ownership while simultaneously dictating the terms (or interventions) of the "enterprise" of self-determination from without. Likewise untrammelled risk exposure is not the final word in resilience parlance and practice (Rosenow, 2012), as in some domains resilience is to be enhanced to reduce exposure. We draw on such diverse deployments precisely to illustrate the varying political 
'projects' underlying specific articulations of resilience. Rather than giving agency to 'resilience' as practitioners sometimes do, or allowing it to maintain coherence as an apparent object, we argue that analyses must explicitly trace the practices that are being re-made through these interventions in specific sites and contexts of articulation. It is through these multiple sites and practices that we have opportunities to politicize resilience multiple.

\section{Conclusions}

We have argued that paying attention to the multiple ways 'resilience' is made to appear as an object illuminates the stakes of contemporary crisis politics. To cite 'resilience' as a solution - to oppression, catastrophe, contingency, ill health, inequality, debt, or environmental degradation - obscures and avoids the frictions of unavoidably antagonistic questions of care, security, and responsibility. Our approach has sought empirical specification of resiliences from different communities of practice so that we might cut into and across its contented post-political generality, arguing that the word must be interrogated at its points of articulation and made to name names. As Mol writes, 'Once we start to look carefully at the variety of the objects performed in a practice, we come across complex interferences between those objects' (1999: 82). Our purpose is not to simply juxtapose and highlight multiple resilience imaginaries but to outline common 'interferences' and points that all resilience articulations must have answers for; namely, their sitings and interventions. We offer these two cuts as starting points for bringing resiliences' visions of care, security, agency, and responsibility into focus. 
What ties social-ecological systems, security and psychology together, is a seeming belief that creating and enhancing something called 'resilience' is the security project (broadly conceived) for the $21^{\text {st }}$ century. As burgeoning critical literatures show, the resilience push evidences fluctuating ways of framing security itself (environmental, economic, psychological, political or otherwise). In distinction to outmoded frames of deterrence and still prominent but contested and uneven ideas of preemption and precaution (see de Goede and Randalls 2009), resilience has maintained a rosy cast even as it suggests the forever-unfinished project of coping and adapting to 'inevitable' instability, disturbances, and vulnerabilities.

Critical geography and politics scholars offer different political projects related to these understandings of vulnerability and expectations of care, responsibility and intervention. From one angle, in reference to governmental interventions and security controls, authors have argued that what we as critics need to emphasize is that life itself is fundamentally vulnerable and uncertain (e.g. Rose, 2014; Amoore, 2013). Here, the enchantment of becoming, or the ultimate inability to capture and harness the uncertain unfolding of life, is held onto as a foothold for crafting more just political futures. From a different vantage point, writers grappling with resilience and contemporary catastrophism, argue that the idea that life is fundamentally vulnerable is nihilistic and post-political and signals further collapses of societal care and political subjectivity (e.g. Evans and Reid, 2014; Žižek, 2010). While it might seem contradictory, we find productive elements in both strands of thought and think that both need to be engaged in a contemporary crisis politics. Not because 'resilience' is death or 
vulnerability or life, but because it is productive of particular conditions of possibility related to knowledge, ideal futures, responsibility, and security.

Ultimately, what 'resilience' is is an articulation of different understandings of societal security; an articulation of desired futures, which are always uncertain, and responsibility for this in the present. Amongst resiliences, different versions of these political stakes are articulated: accepting vulnerability and abandonment, expecting security from governance mechanisms, accepting just survival without political promise or qualification, living vulnerable life with positive projects -- all defined and specified in different, often contradictory, ways. If resilience does have a common thread it is as a term attached to (often implicit) political projects to secure ideal worlds with particular conditions of possibility. Resilience always involves choices and demands, even if the choice is to continue on current paths, perhaps perversely. Sometimes interventions are more obvious and overt, but this is what critical assessments must do; render visible the choices and ideals that the generality of resilience can obscure. 'Resilience,' as we find it at work in the world, isn't anything necessarily; what matters are the futures it imagines, the presents it intervenes upon, and the tactics through which intervention is made.

We think Walker and Cooper (2011) are right to emphasize the degree to which resilience has been and can be deployed toward profoundly conservative ends. This is one ontological siting, where resilience is supposedly found in the survival of the unavoidable and never-ending turbulence of speculative capitalism. There are, however, many other ontological locations of resilience, and this flexibility and generality is what makes it an effective and slick 
frame for mobilizing interventions (or not) without really having to articulate agendas, values, and desires. Our aim is not to resuscitate or rescue resilience but to offer a framework for assessing the implications of this concept so widely wielded to arrange present relations in the name of such divergent visions of the future. Critical assessments of resilience can cut across the generality and evasiveness of the term by nailing it down and forcing the question of specifics when it is summoned, which we maintain is perhaps the only universal moment for politicizing the concept. 


\section{References}

Adams WM (1997) Rationalization and conservation: ecology and the management of nature in the United Kingdom. Transactions of the Institute of British Geographers 22 (3): 277-291.

Adey P and Anderson B (2012) Anticipating emergencies: Technologies of preparedness and the matter of security. Security Dialogue 43(2): 99-117.

American Psychological Association (2008) Resilience in African American children and adolescents: A vision for optimal development. Available at:

http://www.apa.org/pi/cyf/resilience.html (accessed December 2013)

Amin A (2013) Surviving the turbulent future. Environment and Planning D: Society and Space 31: $140-156$.

Amoore L (2013) The Politics of Possibility: Risk and Security Beyond Probability. Durham, NC: Duke University Press.

Anderies JM, Walker BH and Kinzig AP (2006) Fifteen weddings and a funeral: case-studies and resilience based management. Ecology and Society 11(1): 21.

Anderson B (2015) What kind of thing is resilience? Politics 35(1): 60-66. 
Anthony EJ (1987) Risk, vulnerability, and resilience: An overview. In Anthony EJ and Cohler BJ (eds) The invulnerable child. New York: Guilford Press, pp. 3-48.

Aranda K, Zeeman L, Scholes J and Arantxa S-MM (2012) The resilient subject: Exploring subjectivity, identity and the body in narratives of resilience. Health 16(5): 548-563.

Barry A (2006) Technological Zones. European Journal of Social Theory 9(2): 239-253.

Berkes F and Ross H (2013) Community resilience: toward an integrated approach. Society and Natural Resources 26(1): 5-20.

Blaser M (2014) Ontology and indigeneity: on the political ontology of heterogeneous assemblages. cultural geographies 21(1): 49-58.

Cabin RJ 2007. Science-Driven Restoration: A Square Grid on a Round Earth?. Restoration Ecology 15(1): 1-7.

Carpenter S, Walker B, Anderies JM and Abel N (2001) From metaphor to measurement: resilience of what to what? Ecosystems 4: 765-781. 
Castan Broto V and Bulkeley H (2013) Urban governance and climate change experiments. In: Mieg $\mathrm{H}$ and Topfer $\mathrm{K}$ (eds.) Institutional and Social Innovation for Sustainable Urban Development. London: Routledge, pp. 72-87.

Coaffee J (2006) From counterterrorism to resilience. The European Legacy 11(4): 389-403.

Cooper M (2006) Pre-empting Emergence: The Biological Turn in the War on Terror. Theory, Culture \& Society 23(4): 113-135.

Cooper M (2010) Turbulent worlds: Financial markets and environmental crisis. Theory, Culture \& Society 27(2-3): 167-190.

Coulthard S (2012) Can we be both resilient and well, and what choices do people have? Incorporating agency into the resilience debate from a fisheries perspective. Ecology and Society 17(1): 4 .

Cote $\mathrm{M}$ and Nightingale A (2012) Resilience thinking meets social theory: Situating social change in socio-ecological systems (SES) research. Progress in Human Geography 36(4): 475489. 
Davidson DJ (2013) We still have a long way to go, and a short time to get there: a response to Fikret Berkes and Helen Ross. Society and Natural Resources 26(1): 21-24.

de Goede M and Randalls S (2009) Precaution, preemption: Arts and technologies of the actionable future. Environment and Planning D: Society and Space 27(5): 859-878.

Department of Homeland Security (2004) The National Plan for Research and Development In Support of Critical Infrastructure Protection. Washington, D.C. Available at: http://www.dhs.gov/xlibrary/assets/ST_2004_NCIP_RD_PlanFINALApr05.pdf (Accessed June 2014)

Department of Homeland Security (2009) Powering American Cities in the New Century. DHS Science and Technology Snapshots. Available at: http://www.dhs.gov/powering-americancities-new-century (Accessed June 2014)

Department of Homeland Security (2010) Risk and Resilience: Exploring the Relationship. Washington, DC: DHS Science and Technology Directorate.

Dikeç M (2005) Space, politics, and the political. Environment and Planning D: Society and Space 23(2): 171-188. 
ENISA: European Network and Information Security Agency. 2011. Inter-X: Resilience and the Internet Interconnection Ecosystem. Summary Report. Available at: www.enisa.europa.eu

Evans JP 2013. Resilience, ecology and adaptation in the experimental city. Transactions of the Institute of British Geographers 36, 223-237.

Evans B \& Reid J (2014) Resilient Life: The Art of Living Dangerously. Cambridge: Polity Press.

Foucault M (2002) The Order of Things. London: Routledge.

Garmezy N, Masten AS and Tellegen A (1984) The Study of Stress and Competence in Children: A Building Block for Developmental Psychopathology. Child Development 55(1): 97-111.

Gross M (2010) Ignorance and Surprise: Science, Society and Ecological Surprise. Cambridge, MA: MIT Press.

Grove K (2014) Agency, affect, and the immunological politics of disaster resilience.

Environment and Planning D: Society and Space 32(2): 240-256.

Gunderson L and Holling CS (2002) Panarchy: Understanding Transformations in Human and Natural Systems. Washington, DC: Island Press. 
Holling CS (1973) Resilience and the stability of ecological systems. Annual Review of Ecology and Systematics 4: 1-23.

Homeland Security Institute (2009) Public Role and Engagement in Counterterrorism Efforts: Implications of Israeli Practices for the U.S. Arlington, VA: Homeland Security Institute.

Joseph J (2013) Resilience as embedded neoliberalism: A governmentality approach. Resilience: International Policies, Practices and Discourses 1(1): 38-52.

Landau J (2007) Enhancing resilience: Families and communities as agents for change. Family Process 46(3): 351-365.

Larned, JG (2012) Becoming more resilient. FBI Law Enforcement Bulletin October. Available at: http://www.fbi.gov/stats-services/publications/law-enforcement-bulletin/october2012/becoming-more-resilient (Accessed October 2014).

Larner W (2011) C-change? Geographies of crisis. Dialogues in Human Geography 1(3): 319335. 
Law J (2002) Aircraft Stories: Decentering the Object in Technoscience. Durham, NC: Duke University Press.

Little RG (2004) Holistic Strategy for Urban Security. Journal of Infrastructure Systems 10(2): 52-59.

Lorimer J and Driessen C (2013) Bovine biopolitics and the promise of monsters in the rewilding of Heck cattle. Geoforum 48:249-259.

MacKinnon D and Derickson KD (2012) From resilience to resourcefulness: A critique of resilience policy and activism. Progress in Human Geography 37(2): 253-270.

Massumi B (2008) National Enterprise Emergency: Steps Toward an Ecology of Powers. Theory, Culture \& Society 26(6): 153-185.

Michael T (2012) Protecting the Electric Grid. Innovation 10(5). Available at:

http://www.innovation-america.org/protecting-electric-grid (Accessed October 2014)

Mirowski P (2013) Never Let a Serious Crisis Go to Waste: How Neoliberalism Survived the Financial Meltdown. London: Verso. 
Mol A (1999) Ontological politics: A word and some questions. Sociological Review 47: 74-89.

Mol A (2002) The Body Multiple: Ontology in Medical Practice. Durham, NC: Duke University Press.

Nadasdy P (2007) Adaptive Co-Management and the Gospel of Resilience. In: Armitage D, Berkes F and Doubleday N (eds) Adaptive Co-Management: Collaboration, Learning, and MultiLevel Governance. Vancouver, BC: University of British Columbia Press, pp: 208-227.

Nelson SH (2014) Resilience and the neoliberal counter-revolution: from ecologies of control to production of the common. Resilience: International Policies, Practices and Discourses 2(1): 117.

Neocleous M (2012) ‘Don’t be scared, be prepared': Trauma-Anxiety-Resilience. Alternatives: Global, Local, Political 37(3): 188-98.

O'Malley P (2010) Resilient subjects: uncertainty, welfare and liberalism. Economy and Society 39(4): 488-509. 
Phelan L, Henderson-Sellars A and Taplin R (2013) The Political Economy of Addressing the Climate Crisis in the Earth System: Undermining Perverse Resilience. New Political Economy 18(2): 198-226.

Reghezza-Zitt M, Rufat S, Djament-Tran G, Le Blanc and Lhomme S (2012) What resilience is not: uses and abuses. Cybergeo: European Journal of Geography 621. Available at: http://cybergeo.revues.org/25554 (Accessed January 2015).

Reid J (2012) The disastrous and politically debased subject of resilience. Development Dialogue 58: 67-79.

Rose M (2014) Negative governance: vulnerability, biopolitics and the origins of government. Transactions of the Institute of British Geographers 39(2): 209-223.

Rosenow D (2012) Dancing life into being: Genetics, resilience and the challenge of complexity theory. Security Dialogue 43(6): 531-547.

Seccombe K (2002) "Beating the Odds" Versus "Changing the Odds": Poverty, Resilience, and Family Policy. Journal of Marriage and Family 64(2): 384-394. 
Spencer MB (2006) Phenomenology and ecological systems theory: Development of diverse groups. In Lerner RM (ed.), Handbook of Child Psychology: Vol. 1. Theoretical models of human development (6th edition). New York: Wiley, pp. 829-893.

Swyngedouw E (2010) Apocalypse forever? Theory, Culture \& Society 27(2-3): 213-232.

Thomsen DC, Smith, TF and Keys N (2012) Adaptation or Manipulation? Unpacking Climate Change Response Strategies. Ecology and Society 17(3), article 20.

Ungar M (2011) The Social Ecology of Resilience: Addressing Contextual and Cultural Ambiguity of a Nascent Construct. American Journal of Orthopsychiatry 81(1): 1-17.

Walker B (2009) What is resilience in people and ecosystems? Stockholm Resilience Centre Whiteboard Series. Video seminar available at:

http://www.youtube.com/watch?v=tXLMeL5nVQk (Accessed October 2014).

Walker B, Gunderson L, Kinzig A, Folke C, Carpenter S and Schultz L (2006) A handful of heuristics and some propositions for understanding resilience in socio-ecological systems. Ecology and Society 11(1): 13.

Walker J and Cooper M (2011) Genealogies of resilience: From systems ecology to the 
political economy of crisis adaptation. Security Dialogue 42(2): 143-160.

Wilson G (2012) Community resilience, globalization, and transitional pathways. Geoforum 43: $1218-1231$.

World Resources Report (2008) The Roots of Resilience: Growing the Wealth of the Poor. Available at: http://pdf.wri.org/world_resources_2008_roots_of_resilience.pdf (Accessed October 2014)

Young O (2010) Institutional Dynamics: Emergent Patterns in International Environmental Governance. Cambridge, MA: MIT Press.

Zimmerer K (2000) The Reworking of Conservation Geographies: Nonequilibrium Landscapes and Nature-Society Hybrids. Annals of the Association of American Geographers 90(2): 356-369.

Žižek S (1999) The Ticklish Subject: The Absent Centre of Political Ontology. London: Verso.

Žižek S (2001) Psychoanalysis and the post-political: An interview with Slavoj Zizek. New Literary History 32(1): 1-21.

Žižek S (2010) Living in the End Times. London: Verso. 
${ }^{\mathrm{i}}$ Available here: $\underline{w w w} \cdot$ resiliencescale.com/en/rstest/rstest 14 en.html (last accessed October 2014)

ii Psychological resilience literature rarely makes explicit reference to Holling but it has developed its own notions of 'ecosystemic' resilience, or understanding individual resilience as entangled with environmental contexts (e.g. Spencer 2006). 